Article

\title{
Predictors of Dietary Energy Density among Preschool Aged Children
}

\author{
Nilmani N.T. Fernando ${ }^{1}$, Karen J. Campbell ${ }^{2}$, Sarah A. McNaughton ${ }^{2}$, Miaobing Zheng ${ }^{2}$ and \\ Kathleen E. Lacy ${ }^{2, *}$ id \\ 1 School of Exercise and Nutrition Sciences, Deakin University, Burwood, VIC 3125, Australia; \\ tnfernan@deakin.edu.au \\ 2 Institute for Physical Activity and Nutrition (IPAN), School of Exercise and Nutrition Sciences, \\ Deakin University, Geelong, VIC 3220, Australia; karen.campbell@deakin.edu.au (K.J.C.); \\ sarah.mcnaughton@deakin.edu.au (S.A.M.); j.zheng@deakin.edu.au (M.Z.) \\ * Correspondence: katie.lacy@deakin.edu.au; Tel.: +61-352-273-477
}

Received: 22 November 2017; Accepted: 2 February 2018; Published: 6 February 2018

\begin{abstract}
Childhood obesity is a global problem with many contributing factors including dietary energy density (DED). This paper aims to investigate potential predictors of DED among preschool aged children in Victoria, Australia. Secondary analysis of longitudinal data for 209 mother-child pairs from the Melbourne Infant Feeding, Activity and Nutrition Trial was conducted. Data for predictors (maternal child feeding and nutrition knowledge, maternal dietary intake, home food availability, socioeconomic status) were obtained through questionnaires completed by first-time mothers when children were aged 4 or 18 months. Three 24-h dietary recalls were completed when children were aged $~ 3.5$ years. DED was calculated utilizing three methods: "food only", "food and dairy beverages", and "food and all beverages". Linear regression analyses were conducted to identify associations between predictors and these three measures of children's DED. Home availability of fruits ( $\beta$ : $-0.82 ; 95 \%$ CI: $-1.35,-0.29, p=0.002$ for $\mathrm{DED}_{\text {food }} \beta$ : $-0.42 ; 95 \% \mathrm{CI}:-0.82,-0.02$, $p=0.041$ for $\mathrm{DED}_{\text {food+dairy beverages }}$ ) and non-core snacks $(\beta: 0.11 ; 95 \% \mathrm{CI}: 0.02,0.20, p=0.016$ for $\mathrm{DED}_{\text {food }} ; \beta: 0.09 ; 95 \%$ CI: $0.02,0.15, p=0.010$ for $\mathrm{DED}_{\text {food+dairy beverages }}$ ) were significantly associated with two of the three DED measures. Providing fruit at home early in a child's life may encourage the establishment of healthful eating behaviors that could promote a diet that is lower in energy density later in life. Home availability of non-core snacks is likely to increase the energy density of preschool children's diets, supporting the proposition that non-core snack availability at home should be limited.
\end{abstract}

Keywords: dietary energy density; preschool children; dietary intake; home food availability; non-core snacks; energy dense foods; Australia; 24-h recall

\section{Introduction}

Childhood obesity is a global problem. The World Health Organization estimated that 42 million children aged five years and under were overweight or obese in 2015, and these rates are expected to rise to 70 million by 2025 if current trends continue [1]. In Australia, approximately one in five children aged between two and four years is classified as overweight or obese [2]. Childhood obesity is associated with wide-ranging health and social risks [3] and it tends to track into adolescence and adulthood, with additional risks of negative health outcomes [3,4].

While the etiology of obesity is complex, energy intakes above energy requirements are a key contributor. One aspect of diet that may be particularly important is dietary energy density (DED), which is the concentration of energy in food or food and selected beverages $(\mathrm{kJ} / \mathrm{g})$. A systematic review by the 2010 Dietary Guidelines Advisory Committee in the United States (US) concluded that 
there was moderately strong evidence from longitudinal cohort studies in children and adolescents of a positive association between DED and increased adiposity [5]. Further, a 2016 meta-analysis demonstrated that DED was directly associated with the risk of excess adiposity among children and adolescents [6]. Short-term experimental feeding studies using covert adjustments of energy density demonstrated that energy density influences young children's energy intake [7-10]. Additionally, nationally representative data in the US and large population surveys of children across several European countries showed that young children who consume diets that are lower in energy density have more healthful diets (less fat and sugar; more vegetables and fruits) than peers who consume diets that are higher in energy density [11,12].

The energy density of foods and beverages is influenced by their water content and macronutrient composition. Foods high in water and/or fiber tend to be low in energy density, while foods high in fat tend to be high in energy density. Beverages are generally low in energy density because of their high water content. There are different methods that can be used to calculate DED in order to adjust for the influence of beverages because beverages may disproportionately influence DED values [13]. While there is no consensus on which DED calculation method is most appropriate, calculating DED based on 'food only' is recommended for studies examining relationships with body weight [14]. Dairy beverages are part of a healthy diet as recommended by the Australian Dietary Guidelines [15] and provide substantial (12.5\%) energy in two- to three-year-old children's diets [16]. Given this, it is likely to be important to consider dairy beverages (or dairy alternatives) when assessing DED in young children's diets $[17,18]$.

With increasing evidence indicating that DED influences children's body weight and energy intakes, it is important to identify the predictors of DED in order to better target and inform childhood obesity prevention interventions. Young children's diets develop primarily within the family unit, making it vital to examine how family and demographic characteristics may influence DED [19]. The "Ecological model of predictors of childhood overweight" proposed by Davison and Birch in 2001 [20] is useful for identifying family and demographic characteristics as potential predictors of children's DED. Several potential predictors, including parental nutrition knowledge [21], parental dietary intake [22], home food availability [23], and socioeconomic status [24], have been shown to be associated with various aspects of children's diets; however, little is known about the predictors of children's overall DED [11,12,25]. This study aimed to identify the predictors of DED among a sample of Australian preschool children using age-appropriate DED calculation methods.

\section{Materials and Methods}

\subsection{Study Design and Participants}

This study was a secondary analysis of data from the intervention and control participants in the Melbourne Infant Feeding, Activity and Nutrition Trial (Melbourne InFANT Program). The Melbourne InFANT Program was a cluster randomized controlled trial designed to test an intervention, where first-time parents were educated by experienced dietitians on how to promote healthy eating and active play in early childhood [26]. The intervention began when the children were 4 months of age and lasted until children were 18 months of age, with further data collection occurring at approximate ages 3.5 and 5 years [27]. A total of 542 families were recruited through Maternal and Child Health $(\mathrm{MCH})$ centers within a 60-km radius from Deakin University, Melbourne, Australia [28]. Participants were equally and randomly assigned to either the intervention or control arm. Data were collected from participants who were English speaking and who provided informed consent. Parents were asked to complete questionnaires about their children and themselves at ages 4, 9, and 18 months and 3.5 and 5 years. Parents were also asked to provide three five-pass 24-h dietary recalls administered by telephone interview to record children's dietary intakes when children were aged 9 and 18 months [26] and again at 3.5 and 5 years [27]. Dietary recalls were collected by dietitians on three non-consecutive days including a weekend day. Visual aids were provided prior to the interviews to help parents 
to determine food portion sizes. This is a valid and feasible method to collect dietary data [29-31]. The primary outcomes of the Melbourne InFANT Program are reported elsewhere [28]. Ethics approval was provided by Deakin University Ethics Committee (EC 175-2007) and by the Victorian Office for Children (CDF/07/1138). The current study utilized questionnaire data when children were 4 and 18 months and 3.5 years of age as well as the 24-h dietary recall data when children were 3.5 years of age.

\subsection{Outcome Measure: Dietary Energy Density}

Dietary energy density was assessed using 24-h dietary recall data [13,17] collected when children were approximately 3.5 years of age. Dietary intake data were coded by matching food and beverage items to their nutrient composition using the Australian Food Supplement and Nutrient Database "AUSNUT 2007" which has 4225 food and beverage items [32]. Additionally, the nutrient composition of items not found in the AUSTNUT 2007 database was included and classified according to information from the manufacturing company or the product's nutrition information panel [28].

Dietary energy density was calculated using multiple age-appropriate methods including beverages most likely to be consumed by preschool aged children; food only (no beverages; $\left.\mathrm{DED}_{\text {food }}\right)$, food and dairy beverages $\left(\mathrm{DED}_{\text {food+dairy beverages }}\right)$ and food and all beverages (included water; $\left.\mathrm{DED}_{\text {food+all beverages }}\right)$. Specific AUSNUT 2007 food groups were chosen for the DED food and $\mathrm{DED}_{\text {food+all beverages }}$ variable calculations considering previously published criteria [13,33]. While previous studies have used a DED variable for 'food and milk' $[17,18]$, the variable used in the present study, $\mathrm{DED}_{\text {food+dairy beverages, }}$ included all dairy and dairy-substitute based beverages (e.g., soy, rice, oat beverages), dairy beverage flavorings, infant/toddler formula and breastmilk. More detailed information can be found in Appendix A Table A1, which includes details of the AUSNUT 2007 food codes included and excluded. Energy densities were calculated by dividing the kilojoules consumed by the weight of food (and beverages for $\mathrm{DED}_{\text {food+dairy beverages }}$ and $\mathrm{DED}_{\text {food+all beverages }}$ ) consumed using only the items relevant to each DED variable. As three dietary recall interviews were conducted for each child, daily DED values were calculated and averaged across the recalls.

\subsection{Predictor Measures}

The potential predictors of DED informed by the ecological model of predictors of childhood overweight [20] included: maternal child feeding and nutrition knowledge, maternal dietary intake, home food availability, and socioeconomic status where maternal education was used as a proxy. Maternal child feeding and nutrition knowledge, maternal dietary intake and home food availability were assessed at child age 18 months and maternal education was assessed at child age 4 months but was considered to be a proxy for socioeconomic status at child age 18 months. Table 1 lists the measures and their response options from the Melbourne InFANT Program questionnaires related to the different predictors that were analyzed, alongside the original sources of the measures.

Table 1. List of measures and responses from the Melbourne Infant Feeding, Activity and Nutrition Trial (InFANT) Program questionnaires considered as predictors.

\begin{tabular}{clll}
\hline Predictor & Age Assessed & \multicolumn{1}{c}{ Measure } & Response \\
\hline & & Parenting styles and family characteristics & Source \\
\hline $\begin{array}{c}\text { Maternal child } \\
\text { feeding and } \\
\text { nutrition } \\
\text { knowledge }\end{array}$ & \multirow{2}{*}{$\begin{array}{l}12 \text { items examined mothers' } \\
\text { knowledge of the child feeding and } \\
\text { nutrition messages that were } \\
\text { promoted in the Melbourne }\end{array}$} & $\begin{array}{c}\text { Responses: 'strongly } \\
\text { agree', 'agree', 'disagree' } \\
\text { and 'strongly disagree' }\end{array}$ & $\begin{array}{c}\text { Purpose-designed } \\
\text { items previously used } \\
\text { by Spence et al. [34] }\end{array}$ \\
\hline
\end{tabular}


Table 1. Cont.

\begin{tabular}{|c|c|c|c|c|}
\hline Predictor & Age Assessed & Measure & Response & Source \\
\hline \multirow{4}{*}{$\begin{array}{c}\text { Maternal } \\
\text { dietary intake }\end{array}$} & \multirow{4}{*}{18 months } & $\begin{array}{l}\text { Consumption over the previous } 12 \\
\text { months of } 98 \text { food and beverage items } \\
\text { was assessed. Selected items were } \\
\text { used in this study: }\end{array}$ & \multirow{4}{*}{ 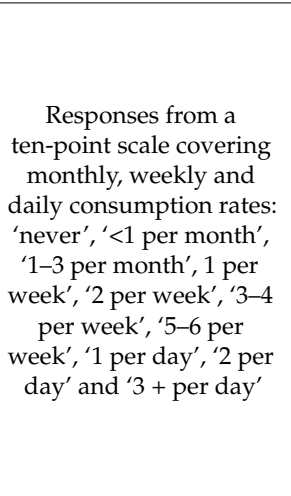 } & \multirow{4}{*}{$\begin{array}{c}\text { Adapted from Cancer } \\
\text { Council Victoria food } \\
\text { frequency } \\
\text { questionnaire [35] }\end{array}$} \\
\hline & & fruits & & \\
\hline & & $\begin{array}{l}\text { non-core sweet snacks (cakes, sweet } \\
\text { biscuits, ice cream, chocolate, } \\
\text { other confectionary) }\end{array}$ & & \\
\hline & & $\begin{array}{l}\text { non-core savoury snacks } \\
\text { (non-wholemeal crackers, } \\
\text { chips, crisps) }\end{array}$ & & \\
\hline \multirow{6}{*}{$\begin{array}{l}\text { Home food } \\
\text { availability }\end{array}$} & \multirow{6}{*}{18 months } & fruits & \multirow{6}{*}{$\begin{array}{c}\text { Responses: 'never', } \\
\text { 'sometimes', 'usually', } \\
\text { 'always' }\end{array}$} & \multirow{6}{*}{$\begin{array}{c}\text { Adapted from } \\
\text { Macfarlane et al. [36] }\end{array}$} \\
\hline & & vegetables other than potato, & & \\
\hline & & chocolates or lollies & & \\
\hline & & cakes/donuts/sweet biscuits & & \\
\hline & & potato chips or salty snacks & & \\
\hline & & $\begin{array}{l}\text { fruit juice and soft/sweetened } \\
\text { beverages }\end{array}$ & & \\
\hline \multicolumn{5}{|c|}{ Community, demographical and societal characteristics } \\
\hline
\end{tabular}

Maternal knowledge of child feeding and nutrition was assessed using 12 questions related to the child feeding and nutrition intervention messages that were promoted in the Melbourne InFANT Program. Using methods similar to Spence et al. [34], correct answers were given a score of one and incorrect responses a score of zero and an overall summary score was calculated with a maximum score of 12. The total score for the 12 items was shown to have an intraclass correlation of 0.73 in test-retest assessments using a separate sample of 51 mothers with children aged approximately 18 months. Because total scores were non-normally distributed, a new dichotomous variable was created grouping mothers scoring at least 11 or scoring less than 11.

Maternal dietary intake was measured using the Cancer Council Victoria food frequency questionnaire (FFQ), Version 3 [35]. The questions included 98 foods and beverages, with responses ranging from 'never' to 'three + per day'. For the present study, only intakes of fruits, vegetables, non-core sweet snacks, non-core savory snacks, and non-core drinks were analyzed because these groups represent major sources of foods in children's diets and capture both ends of the energy density continuum. New dichotomous variables were created for each of the food groups using methods similar to those of Spence et al. [34]. Fruit consumption was dichotomized as per the Australian Dietary Guidelines [15], with mothers who reported consuming two or more servings per day grouped together and those consuming less than two serves per day grouped together. As few mothers met the Australian Dietary Guideline for vegetables (five servings per day) [15], vegetable consumption was dichotomized at three or more servings per day. Non-core sweet snacks consumption was dichotomized at one or more servings per day and non-core savory snacks consumption was dichotomized at one or more servings per week. Non-core drinks consumption was dichotomized at one or more glasses per day. 
Home food availability was measured using seven questions completed by mothers. Four variables were created representing fruits, vegetables, non-core snacks and non-core drinks using methods similar to those of Collins et al. [37]. Vegetable and fruit availability were dichotomized as 'always' and 'never/sometimes/usually' available. The composite variable for non-core snacks was a summary score of the three items on chocolates or lollies, potato chips or salty snacks and cakes/donuts/sweet biscuits and was treated as a continuous variable with a maximum score of nine. Similarly, the composite variable for non-core drinks was a summary score of the two items on fruit juice and soft/sweetened beverages and was treated as a continuous variable with a maximum score of six.

Maternal education level was self-reported using one question where mothers indicated their highest education level. A dichotomous variable was created grouping mothers with more than or less than university education [38].

\subsection{Covariates}

Covariates for this study included: child's sex (data collected through questionnaires completed by child's parent when child was aged 4 months) and child's age (data collected for covariate through questionnaires completed by parent when the child was around 3.5 years of age). As data were from both the intervention and control arms of the Melbourne InFANT Program, treatment arm was also used as a covariate. These covariates were included in all bivariate and multivariable linear regression models. The DAGitty program, version 2.3 (http:/ / www.dagitty.net/dags.html) was used to identify additional potential confounding factors for each predictor [39] and these were included in multivariable linear regression analyses as appropriate.

\subsection{Statistical Analysis}

A total of 261 parent-child pairs participated in data collection when children were approximately 3.5 years of age. Exclusion criteria were applied excluding pairs where the mother was not a first-time mother (8 pairs) and where children had fewer than three five-pass 24-h dietary recalls at 3.5 years (5 pairs). Participants were excluded for missing data on the potential predictors: maternal child feeding and nutrition knowledge (11 pairs), maternal dietary intake (6 pairs), home food availability ( 1 pair) and maternal education (0 pairs). Further, participants were excluded when children had fewer than three five-pass 24 -h dietary recalls at 18 months (18 pairs). Participants whose average energy intake exceeded the average energy intake of $5329 \pm 1219$ kilojoules by three or more standard deviations ( 3 pairs) were excluded. After excluding participants according to the above criteria, the final sample was 209 mother-child pairs.

Using IBM SPSS Statistics (version 24, 2016, IBM-SPSS Inc., Armonk, NY, USA), descriptive analysis was conducted to assess participants' characteristics. Bivariate linear regression models were performed to examine the association between individual predictors and DED with adjustment for covariates including child sex, child age and treatment arm. Multivariable regression models including the previously described potential confounders were conducted to assess independent effects of each predictor on DED. These regression models controlled for DED at child 18 months, thus ensuring any associations seen were not due to baseline diet. The three DED variables were used as continuous outcomes, and separate models were fitted for the three DED measures. STATA statistical software (version 14, 2015, Stat Corp., College Station, TX, USA) was used to perform bivariate and multivariable linear regressions specifying parent groups as random effects to account for clustering.

\section{Results}

\subsection{Sample Characteristics}

Overall, children had a mean age of $3.5 \pm 0.2$ years with a slightly higher percentage of girls compared with boys ( $51 \%$ vs. $49 \%$ ) (Table 2 ). There were slightly more children from the intervention arm of the study compared with the control arm (51\% vs. $49 \%)$. Children had an average BMI $z$-score 
of $0.71 \pm 0.89$ and the average dietary energy intake including fiber was $5266 \pm 1110 \mathrm{~kJ}$. Overall, there was an overrepresentation of mothers with university or higher degrees (64\%) relative to mothers with less education $(36 \%)$.

Table 2. Characteristics of children, mothers and homes in the Melbourne InFANT Program.

\begin{tabular}{|c|c|}
\hline Child Characteristics & Values \\
\hline \multicolumn{2}{|l|}{ Energy intake $(\mathrm{kJ})$} \\
\hline Mean \pm SD & $5266 \pm 1110$ \\
\hline Range & $3050-8752$ \\
\hline \multicolumn{2}{|l|}{ Energy density-Food only (kJ/g) } \\
\hline Mean \pm SD & $6.42 \pm 1.18$ \\
\hline Range & $3.92-10.05$ \\
\hline \multicolumn{2}{|l|}{ Energy density_Food and dairy beverages $(\mathrm{kJ} / \mathrm{g})$} \\
\hline Mean \pm SD & $5.35 \pm 0.90$ \\
\hline Range & $3.43-8.45$ \\
\hline \multicolumn{2}{|l|}{ Energy density-Food and all beverages $(\mathrm{kJ} / \mathrm{g})$} \\
\hline Mean \pm SD & $3.38 \pm 0.71$ \\
\hline Range & $1.21-6.36$ \\
\hline \multicolumn{2}{|l|}{ Child's age (years) } \\
\hline Mean $\pm \mathrm{SD}$ & $3.5 \pm 0.2$ \\
\hline Range & $3.2-4.2$ \\
\hline \multicolumn{2}{|l|}{ Child's sex } \\
\hline Male, $n(\%)$ & $103(49)$ \\
\hline Female, $n(\%)$ & $106(51)$ \\
\hline \multicolumn{2}{|l|}{ Treatment arm } \\
\hline Intervention $n(\%)$ & $107(51)$ \\
\hline Control $n(\%)$ & $102(49)$ \\
\hline \multicolumn{2}{|l|}{ Body mass index $z$ score } \\
\hline Mean \pm SD & $0.71 \pm 0.89$ \\
\hline Range & $-1.94-4.04$ \\
\hline \multicolumn{2}{|c|}{ Maternal and home characteristics } \\
\hline \multicolumn{2}{|c|}{ Maternal child feeding and nutrition knowledge assessed when the child was 18 months } \\
\hline$>11$ (possible score 12 ), $n(\%)$ & $77(37)$ \\
\hline$<11$ (possible score 12$), n(\%)$ & $132(63)$ \\
\hline \multicolumn{2}{|l|}{ Maternal dietary intake assessed when the child was 18 months } \\
\hline \multicolumn{2}{|l|}{ Fruits } \\
\hline$\geq 2$ servings/day, $n(\%)$ & $114(55)$ \\
\hline$<2$ servings/day, $n(\%)$ & $95(45)$ \\
\hline \multicolumn{2}{|l|}{ Vegetables } \\
\hline$\geq 3$ servings/day, $n(\%)$ & $111(53)$ \\
\hline$<3$ servings/day, $n(\%)$ & $98(47)$ \\
\hline \multicolumn{2}{|l|}{ Non-core sweet snacks } \\
\hline$\geq 1$ servings/day, $n(\%)$ & $84(40)$ \\
\hline$<1$ servings/day, $n(\%)$ & $125(60)$ \\
\hline \multicolumn{2}{|l|}{ Non-core savoury snacks } \\
\hline$\geq 1$ servings/week, $n(\%)$ & $105(50)$ \\
\hline$<1$ servings/week, $n(\%)$ & $104(50)$ \\
\hline \multicolumn{2}{|l|}{ Non-core drinks } \\
\hline$\geq 1$ servings/day, $n(\%)$ & $72(34)$ \\
\hline$<1$ servings/day, $n(\%)$ & $137(66)$ \\
\hline \multicolumn{2}{|l|}{ Home food availability assessed when child was 18 months } \\
\hline \multicolumn{2}{|l|}{ Fruits } \\
\hline Always, $n(\%)$ & $190(91)$ \\
\hline Never/sometimes/usually, $n(\%)$ & $19(9)$ \\
\hline Vegetables & \\
\hline Always, $n(\%)$ & $193(92)$ \\
\hline Never/sometimes/usually, $n(\%)$ & $16(8)$ \\
\hline Non-core snacks (possible score from 0 to 9 ) & \\
\hline Median (IQR) & $3.0(3.0,4.0)$ \\
\hline Range & $0.0-9.0$ \\
\hline Non-core drinks (possible score from 0 to 6 ) & \\
\hline Median (IQR) & $2.0(2.0,4.0)$ \\
\hline Range & $0.0-6.0$ \\
\hline Maternal education assessed when the child was assessed & \\
\hline Less than university, $n(\%)$ & $75(36)$ \\
\hline University or higher degree, $n(\%)$ & $134(64)$ \\
\hline
\end{tabular}




\subsection{Bivariate and Multivariable Linear Regression Analysis}

Bivariate linear regressions showed significant associations between $\mathrm{DED}_{\text {food }}$ and maternal intake of fruits and home availability of fruits and non-core snacks (Table 3). Maternal intake of fruits ( $\beta$ : $-0.39 ; 95 \%$ CI: $-0.69,-0.08 ; \beta=0.012)$ and home availability of fruits $(\beta:-0.82 ; 95 \% \mathrm{CI}$ : $-1.35,-0.29, p=0.002$ ) had inverse associations in both bivariate and multivariable analyses. Home availability of non-core snacks ( $\beta$ : $0.11 ; 95 \%$ CI: $0.02,0.20, p=0.016)$ was positively associated with children's DED in both bivariate and multivariable analyses.

Linear regressions showed significant associations between $\mathrm{DED}_{\text {food+dairy beverages }}$ and home availability of fruits and non-core snacks and maternal education used as an indicator of socioeconomic status (Table 4$)$. Home availability of fruits ( $\beta$ : $-0.42 ; 95 \% \mathrm{CI}:-0.82,-0.02, p=0.041)$ and maternal education ( $\beta$ : $-0.24 ; 95 \% \mathrm{CI}:-0.48,-0.01 ; p=0.044)$ were inversely associated with children's DED in both bivariate and multivariable analyses. Home availability of non-core snacks ( $\beta$ : 0.09 ; $95 \%$ CI: $0.02,0.15, p=0.010$ ) showed positive associations with children's DED for both bivariate and multivariable analyses.

Home food availability of fruits and non-core snacks showed significant associations with children's $\mathrm{DED}_{\text {food+all beverages }}$ (Table 5). When bivariate analyses were conducted, home availability of fruits was inversely associated with children's DED and home availability of non-core snacks was positively associated with children's DED. However, neither predictor remained significant in multivariable analysis. 
Table 3. Results of bivariate and multivariable linear regression analyses among children participating in the Melbourne InFANT Program $(n=209)$ for the predictors and the dietary energy density variable dietary energy density from food $\left(\mathrm{DED}_{\mathrm{food}}\right)$.

\begin{tabular}{|c|c|c|c|c|c|c|}
\hline \multirow{2}{*}{ Predictor } & \multicolumn{3}{|c|}{ Bivariate Regression $^{1}$} & \multicolumn{3}{|c|}{ Multivariable Regression 1,2 } \\
\hline & $\beta$ Coefficient & 95\% Confidence Interval & $p$ Value $^{3}$ & $\beta$ Coefficient & 95\% Confidence Interval & $p$ Value \\
\hline \multicolumn{7}{|c|}{ Parenting styles and family characteristics } \\
\hline $\begin{array}{l}\text { Maternal child feeding and nutrition knowledge } \\
\text { assessed when the child was age } 18 \text { months }\end{array}$ & -0.277 & $-0.612-0.057$ & 0.104 & -0.127 & $-0.453-0.198$ & 0.444 \\
\hline \multicolumn{7}{|c|}{ Maternal dietary intake assessed when the child was age 18 months } \\
\hline Fruits ( $\geq 2$ servings/day) & -0.476 & $-0.787--0.166$ & 0.003 & -0.386 & $-0.688--0.085$ & 0.012 \\
\hline Vegetables ( $\geq 3$ servings/day) & -0.097 & $-0.414-0.221$ & 0.551 & -0.026 & $-0.331-0.278$ & 0.865 \\
\hline Non-core sweet snacks ( $\geq 1$ serves/day) & 0.312 & $-0.007-0.631$ & 0.055 & 0.322 & $0.018-0.625$ & 0.038 \\
\hline Non-core savoury snacks ( $\geq 1$ serves/week) & 0.106 & $-0.211-0.423$ & 0.513 & 0.029 & $-0.274-0.333$ & 0.849 \\
\hline Non-core drinks ( $\geq 1$ servings/day) & 0.190 & $-0.138-0.518$ & 0.257 & 0.103 & $-0.212-0.418$ & 0.520 \\
\hline \multicolumn{7}{|c|}{ Home food availability assessed when child was age 18 months } \\
\hline Fruits & -1.015 & $-1.558--0.472$ & $<0.001$ & -0.823 & $-1.353--0.293$ & 0.002 \\
\hline Vegetables & -0.470 & $-1.057-0.118$ & 0.117 & -0.317 & $-0.878-0.244$ & 0.268 \\
\hline Non-core snacks & 0.139 & $0.048-0.230$ & 0.003 & 0.109 & $0.021-0.196$ & 0.016 \\
\hline Non-core drinks & 0.059 & $-0.045-0.163$ & 0.267 & 0.048 & $-0.052-0.147$ & 0.347 \\
\hline \multicolumn{7}{|c|}{ Community, demographic and societal characteristics } \\
\hline $\begin{array}{l}\text { Socioeconomic status assessed when the child } \\
\text { was age } 4 \text { months }\end{array}$ & -0.262 & $-0.593-0.068$ & 0.120 & -0.142 & $-0.460-0.177$ & 0.384 \\
\hline
\end{tabular}

${ }^{1}$ all bivariate and multivariable regression models included child sex and age, treatment arm and clustering by first-time parent group; ${ }^{2}$ all multivariable regression models included children's $\mathrm{DED}_{\text {food }}$ at child age 18 months. The model for the predictor maternal child feeding and nutrition knowledge was adjusted for maternal education [40]. The models for maternal dietary intake predictors were adjusted for maternal child feeding and nutrition knowledge and maternal education [41]. The models for home food availability predictors were adjusted for maternal child feeding and nutrition knowledge and maternal education [42]. The model for predictor maternal education had no additional adjustments; ${ }^{3}$ all bolded results show significant associations $(p \leq 0.05)$ 
Table 4. Results of bivariate and multivariable linear regression analyses among children participating in the Melbourne InFANT Program $(n=209)$ for the predictors and the dietary energy density variable dietary energy density from food and dairy beverages $\left(\mathrm{DED}_{\text {food+dairy beverages }}\right)$.

\begin{tabular}{|c|c|c|c|c|c|c|}
\hline \multirow{2}{*}{ Predictor } & \multicolumn{3}{|c|}{ Bivariate Regression ${ }^{1}$} & \multicolumn{3}{|c|}{ Multivariable Regression ${ }^{1,2}$} \\
\hline & $\beta$ Coefficient & 95\% Confidence Interval & $p$ Value $^{3}$ & $\beta$ Coefficient & 95\% Confidence Interval & $p$ Value \\
\hline \multicolumn{7}{|c|}{ Parenting styles and family characteristics } \\
\hline $\begin{array}{l}\text { Maternal child feeding and nutrition knowledge } \\
\text { assessed when the child was age } 18 \text { months }\end{array}$ & -0.219 & $-0.473-0.036$ & 0.092 & -0.113 & $-0.355-0.130$ & 0.362 \\
\hline \multicolumn{7}{|c|}{ Maternal dietary intake assessed when the child was age 18 months } \\
\hline Fruits ( $\geq 2$ servings/day) & -0.207 & $-0.448-0.034$ & 0.093 & -0.135 & $-0.364-0.094$ & 0.249 \\
\hline Vegetables ( $\geq 3$ servings/day) & 0.061 & $-0.183-0.305$ & 0.624 & 0.129 & $-0.100-0.357$ & 0.271 \\
\hline Non-core sweet snacks ( $\geq 1$ serves/day) & 0.231 & $-0.013-0.475$ & 0.064 & 0.288 & $0.061-0.515$ & 0.013 \\
\hline Non-core savoury snacks ( $\geq 1$ serves/week) & 0.183 & $-0.057-0.422$ & 0.135 & 0.126 & $-0.100-0.352$ & 0.275 \\
\hline Non-core drinks ( $\geq 1$ serves/day) & 0.252 & $0.001-0.503$ & 0.049 & 0.185 & $-0.051-0.421$ & 0.124 \\
\hline \multicolumn{7}{|c|}{ Home food availability assessed when child was age 18 months } \\
\hline Fruits & -0.497 & $-0.921--0.073$ & 0.022 & -0.417 & $-0.817--0.017$ & 0.041 \\
\hline Vegetables & -0.191 & $-0.643-0.260$ & 0.406 & -0.072 & $-0.494-0.349$ & 0.737 \\
\hline Non-core snacks & 0.109 & $0.040-0.179$ & 0.002 & 0.086 & $0.021-0.152$ & 0.010 \\
\hline Non-core drinks & 0.037 & $-0.043-0.116$ & 0.368 & 0.029 & $-0.046-0.104$ & 0.447 \\
\hline \multicolumn{7}{|c|}{ Community, demographic and societal characteristics } \\
\hline $\begin{array}{l}\text { Socioeconomic status assessed when the child } \\
\text { was age } 4 \text { months }\end{array}$ & -0.297 & $-0.548--0.046$ & 0.020 & -0.244 & $-0.481--0.007$ & 0.044 \\
\hline
\end{tabular}

${ }^{1}$ all bivariate and multivariable regression models included child sex and age, treatment arm and clustering by first-time parent group; ${ }^{2}$ all multivariable regression models included children's $\mathrm{DED}_{\text {food+dairy beverages }}$ at child age 18 months. The model for the predictor maternal child feeding and nutrition knowledge was adjusted for maternal education [40]. The models for maternal dietary intake predictors were adjusted for maternal child feeding and nutrition knowledge and maternal education [41]. The models for home food availability predictors were adjusted for maternal child feeding and nutrition knowledge and maternal education [42]. The model for predictor maternal education had no additional adjustments; ${ }^{3}$ all bolded results show significant associations $(p \leq 0.05)$. 
Table 5. Results of bivariate and multivariable linear regression analyses among children participating in the Melbourne InFANT Program $(n=209)$ for the predictors and the dietary energy density variable dietary energy density from food and all beverages (DED food+all beverages $)$.

\begin{tabular}{|c|c|c|c|c|c|c|}
\hline \multirow{2}{*}{ Predictor } & \multicolumn{3}{|c|}{ Bivariate Regression ${ }^{1}$} & \multicolumn{3}{|c|}{ Multivariable Regression ${ }^{1,2}$} \\
\hline & $\beta$ Coefficient & 95\% Confidence Interval & $p$ Value $^{3}$ & $\beta$ Coefficient & 95\% Confidence Interval & $p$ Value \\
\hline \multicolumn{7}{|c|}{ Parenting styles and family characteristics } \\
\hline $\begin{array}{l}\text { Maternal child feeding and nutrition knowledge } \\
\text { assessed when the child was age } 18 \text { months }\end{array}$ & -0.039 & $-0.240-0.162$ & 0.704 & 0.037 & $-0.148-0.223$ & 0.694 \\
\hline \multicolumn{7}{|c|}{ Maternal dietary intake assessed when the child was age 18 months } \\
\hline Fruits ( $\geq 2$ servings/day) & -0.067 & $-0.256-0.123$ & 0.490 & -0.087 & $-0.262-0.087$ & 0.327 \\
\hline Vegetables ( $\geq 3$ servings/day) & -0.088 & $-0.278-0.102$ & 0.365 & -0.046 & $-0.221-0.130$ & 0.610 \\
\hline Non-core sweet snacks ( $\geq 1$ serves/day) & 0.159 & $-0.032-0.351$ & 0.103 & 0.068 & $-0.110-0.245$ & 0.456 \\
\hline Non-core savoury snacks ( $\geq 1$ serves/week) & 0.048 & $-0.141-0.238$ & 0.616 & 0.022 & $-0.152-0.195$ & 0.806 \\
\hline Non-core drinks ( $\geq 1$ serves / day) & -0.040 & $-0.237-0.157$ & 0.694 & -0.085 & $-0.265-0.096$ & 0.356 \\
\hline \multicolumn{7}{|c|}{ Home food availability assessed when child was age 18 months } \\
\hline Fruits & -0.413 & $-0.743--0.082$ & 0.014 & -0.233 & $-0.544-0.079$ & 0.143 \\
\hline Vegetables & -0.249 & $-0.601-0.104$ & 0.166 & -0.092 & $-0.416-0.233$ & 0.579 \\
\hline Non-core snacks & 0.084 & $0.030-0.139$ & 0.002 & 0.046 & $-0.006-0.098$ & 0.081 \\
\hline Non-core drinks & -0.003 & $-0.066-0.059$ & 0.919 & 0.000 & $-0.057-0.057$ & 0.990 \\
\hline \multicolumn{7}{|c|}{ Community, demographic and societal characteristics } \\
\hline $\begin{array}{l}\text { Socioeconomic status assessed when the child } \\
\text { was age } 4 \text { months }\end{array}$ & 0.014 & $-0.185-0.213$ & 0.891 & 0.049 & $-0.132-0.229$ & 0.598 \\
\hline
\end{tabular}

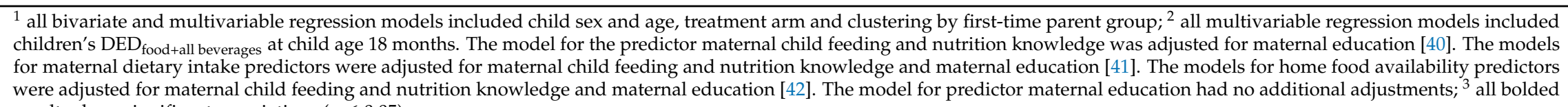
results show significant associations $(p<0.05)$. 


\section{Discussion}

This study aimed to investigate potential predictors of DED among preschool aged children. There were several significant relationships between the potential predictors and the energy density variables but the most consistent relationships were those between home availability of fruits and non-core snacks with DED, with significant associations found for $\mathrm{DED}_{\text {food }}$ and $\mathrm{DED}_{\text {food+dairy beverages. }}$ Mean DED values were slightly lower for children in the present study than those reported among preschool children in the US [17].

Home availability of non-core snacks was predictive of preschool aged children's DED food and $\mathrm{DED}_{\text {food+dairy beverages }}$ and there was an inverse association between home availability of fruits and

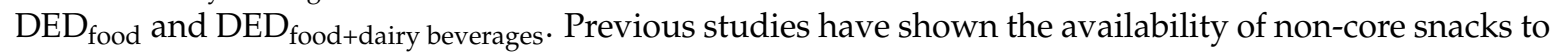
have a positive association with children's intake of non-core snacks $[43,44]$. Systematic reviews of older children (4-12 years, 6-11 years and 6-18 years) and studies among preschool children have also shown positive associations between home availability of fruits and children's fruit consumption [45-48]. Consuming non-core snacks is problematic as it can reduce children's dietary quality by increasing their intakes of fats and sugars [49]. Children's preferences for non-core foods could also lead to consumption of these foods over core foods when both are available at home [39]. Therefore, it may be important to covertly restrict the availability of non-core snacks in order to moderate DED and promote intakes of fruits and vegetables [50]. Parents should promote healthy home food environments by favoring core foods over non-core foods from early in a child's life.

Maternal dietary intakes of vegetables, non-core sweet or savory snacks and non-core drinks did not predict children's DED. One exception was maternal intake of fruits, which was inversely associated with children's DED food. Several studies have identified positive associations between parents' and children's fruit and vegetable intakes [51-53]. The lack of significant results for maternal intake of vegetables, non-core sweet or savory snacks and non-core drinks and children's DED could be due to differences in how dietary data were collected (three 24-h dietary records for children and food frequency questionnaires for the past 12 months in mothers). It could also be the case that the diet of the father may be important when it comes to some specific foods. Another study using data from the Melbourne InFANT Program found that fathers' intakes of fruits, sweet snacks and sweetened beverages when children were 20 months of age were associated with children's intakes of fruits, sweet snacks and sweetened beverages between 20 months and 3.5 years [54]. It is important to note that DED could be influenced by paternal factors, as studies have found that father's dietary intake of non-core snacks influenced children's consumption of non-core snacks [51,54]. Further studies should consider examining the association between paternal dietary intakes and children's DED.

Maternal education was inversely associated with children's DED $_{\text {food+dairy beverages, which is }}$ consistent with previous research demonstrating that children from lower socioeconomic positions tend to have less healthful diets [55] and children of mothers with higher maternal educational levels tend to consume lower quantities of non-core snacks and more healthy snacks [25]. Kant and Graubard found that the education level of the household head, but not household income, was related to $\mathrm{DED}_{\text {food }}$ (the only DED variable used) for a nationally representative sample of two- to five-year-old children in the US. This suggests family education level may be more important in determining food choices and, therefore, future intervention studies should target increasing education-related knowledge gaps in target populations [25]. Future research should consider using more than one proxy measure to examine socioeconomic backgrounds when examining children's DED [56,57].

$\mathrm{DED}_{\text {food }}$ and $\mathrm{DED}_{\text {food+dairy beverages }}$ tended to have similar values and similar associations with

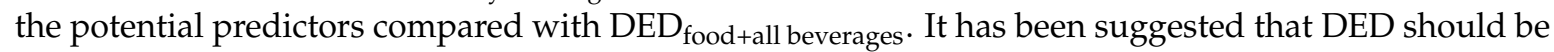
calculated without the inclusion of beverages (e.g., "food only") when focusing on the risk of obesity, as beverages tend to dilute energy densities leading to misinterpretation of results [58-60]. Also, since beverages tend to have lower energy densities (higher water content than macronutrient content) and different levels of satiety in comparison with food items (higher macronutrient content than water content), including beverages in energy density calculations can have a strong effect on overall energy 
density values. It is also important for researchers to agree on which beverages to include/exclude in DED calculations when examining the diets of preschool aged children.

The present study has several strengths, including the use of longitudinal data to identify the associations between multiple early life predictors that could influence the DED of preschool aged children. Dietary energy densities were calculated using three five-pass 24-h dietary recalls, which is the method recommended as the gold standard [29]. Also, this study used multiple DED variables and previously published measures to obtain data on the potential predictors and careful consideration was given to the potential confounders included in multivariable linear regression models. Limitations of this study include that the majority of the Melbourne InFANT Program mothers were highly educated with high child feeding and nutrition knowledge, which may limit the generalizability of results. Further, the diversity of dietary patterns that exists among preschool children [61,62] may not have been captured in the present study. All measures were self- or parent-reported, which could potentially increase social desirability bias and the exclusion of mothers with missing data for the potential predictors may have influenced the statistical analysis. Only mothers' diet was considered a predictor in these analyses, but other potentially important role models of eating, including fathers, grandparents, carers and siblings, could also be influential. Lastly, there may be other relevant predictors that were not included in the present study, such as food accessibility [20] and food availability at child care, that could influence young children's DED.

\section{Conclusions}

Home availability of fruits and non-core snacks influenced the DED of preschool aged children. This suggests that providing fruit at home early in a child's life may encourage the establishment of healthful eating behaviors that could promote a diet that is lower in energy density later in life. Children from homes where non-core snacks were readily available early in life were more likely to consume diets that were higher in energy density even when their mothers had relatively high nutrition knowledge and educational backgrounds. Mothers should be advised to limit the presence of non-core snacks at home early on in their child's life.

Acknowledgments: The Melbourne InFANT Program was funded by contributions by Deakin University, the Australian National Health and Medical Research Council (NHMRC) (grant nos. ID1008879 and ID425801), the National Heart Foundation of Australia, and the Victorian Health Promotion Foundation. S.A.M. is supported by an NHMRC Career Development Fellowship Level 2, ID1104636 and was previously supported by an ARC Future Fellowship (2011-2015, FT100100581).

Author Contributions: K.E.L. and S.A.M. were responsible for the study conception. K.J.C. and S.A.M. were responsible for dietary data collection in their lead investigator roles in the Melbourne InFANT Program. N.N.T.F. wrote the manuscript and performed the data analysis. M.Z., K.E.L. and K.J.C. assisted with data analysis. K.E.L., K.J.C., M.Z. and S.A.M. provided significant consultation and made significant contributions to the manuscript.

Conflicts of Interest: The authors declare no conflict of interest.

\section{Appendix A}

Table A1. The food groups that were included and excluded in calculating the three DED variables identified via the AUSTNUT 2007 two-digit, three-digit and five-digit food codes ${ }^{1,2}$.

\begin{tabular}{lll}
\hline Variable & Definition & Austnut 2007 Food Codes \\
\hline & & 12 -Cereals and cereal products \\
& 13 -Cereal-based products and dishes \\
& 14-Fats and oils \\
$\mathrm{DED}_{\text {food }}$ & All solid and liquid & 16 -Fish and seafood products and dishes \\
& based foods & 17-Egg products and dishes \\
& & 18 - Meat, poultry and games. products and dishes \\
& & 21-Soup \\
\hline
\end{tabular}


Table A1. Cont.

\begin{tabular}{|c|c|c|}
\hline Variable & Definition & Austnut 2007 Food Codes \\
\hline $\mathrm{DED}_{\text {food }}$ & $\begin{array}{l}\text { All solid and liquid } \\
\text { based foods }\end{array}$ & $\begin{array}{l}\text { 22-Seed and nut products and dishes (except food code } 22203003 \text {-Coconut, } \\
\text { fresh, mature, water or juice and food code 22204023-Almond milk, with linseed } \\
\text { oil and water) } \\
\text { 23-Savory sauces and condiments } \\
\text { 24-Vegetable products and dishes } \\
\text { 25-Legume and pulse products and dishes } \\
\text { 26-Snack foods } \\
\text { 27-Sugar products and dishes (except food code 27303005-Ice confection drink, } \\
\text { crushed ice with fruit-based flavored syrup (25\% apple juice) and food code } \\
\text { 27303006-Ice confection, } 97 \% \text { fruit juice, tropical (apple, mango, passionfruit } \\
\text { \& banana) } \\
\text { 28-Confectionery and cereal/nut/fruit/seed bars (except food code } \\
\text { 28303-Chewing gum, Sugar sweetened and food code 28304-Chewing gum, } \\
\text { Artificially sweetened) } \\
\text { 19109-Milk, evaporated, undiluted } \\
\text { 192-Yoghurt } \\
\text { 193-Cream } \\
\text { 194-Cheese } \\
\text { 195-Frozen milk products } \\
\text { 196-Custards } \\
\text { 197-Other dishes where milk is a major component } \\
\text { 20101003-Cream, soy } \\
\text { 203-Cheese substitute } \\
\text { 204-Soy-based ice confection } \\
\text { 205-Soy-based yoghurts } \\
\text { 31102-Yeast, vegetable and meat extracts } \\
\text { 31302011-Mustard, cream-style, condiment } \\
\text { 322-Infant cereal products } \\
\text { 323-Infant foods } \\
\text { Excluded major codes were: } \\
\text { 11-Non-alcoholic beverages, } \\
\text { 30-Special dietary foods } \\
\text { 33-Dietary supplements. }\end{array}$ \\
\hline $\begin{array}{l}\mathrm{DED}_{\text {food + dairy }} \\
\text { beverages }\end{array}$ & $\begin{array}{l}\text { All solid and liquid foods } \\
\text { including all dairy and } \\
\text { dairy-substitute based } \\
\text { beverages, dairy } \\
\text { beverage flavorings, } \\
\text { infant/toddler formula } \\
\text { and breastmilk }\end{array}$ & $\begin{array}{l}\text { All food codes included in } \text { DED }_{\text {food }} \text { are included with the below additional codes; } \\
\text { 11801-Fortified dry beverage flavorings } \\
\text { 11802-Fortified beverage flavorings made up, unspecified strength } \\
\text { 11803-Unfortified dry beverage flavorings } \\
\text { 11804-Unfortified beverage flavorings, made up, unspecified strength } \\
\text { 19101-Milk, cow, fluid, fat-increased } \\
\text { 19102-Milk, cow, fluid, regular whole, full fat } \\
\text { 19103-Milk, cow, fluid, regular whole, full fat, fortified } \\
\text { 19104-Milk, cow, fluid, reduced fat, <2\% } \\
\text { 19105-Milk, cow, fluid, reduced fat, <2\%, fortified } \\
\text { 19106-Milk, cow, fluid, skim, non-fat } \\
\text { 19107-Milk, cow, fluid, skim, non-fat, fortified } \\
\text { 19108-Milk, cow, fluid, added substances other than nutrients (e.g., Phytosterols) } \\
\text { 19112-Milk, powder, dry, skim } \\
\text { 19113-Milk, fluid, other (e.g., Goat and Sheep) } \\
\text { 19114-Milk, fluid, unspecified } \\
\text { 19801-Milk, other flavored and milk based drinks, full fat } \\
\text { 19802-Milk, coffee/chocolate flavored and milk-based drinks, full fat } \\
\text { 19803-Milk, other flavored and milk-based drinks, reduced fat } \\
\text { 19804-Milk, coffee/chocolate flavored and milk-based, reduced fat } \\
\text { 20101-Soy-based beverage, plain } \\
\text { 20102-Soy-based beverage, plain, fortified } \\
\text { 20103-Soy-based beverage, plain, reduced fat } \\
\text { 20104-Soy-based beverage, plain, reduced fat, fortified } \\
\text { 20105-Soy-based, plain, skim } \\
\text { 20106 - Soy-based beverage, plain, skim, fortified } \\
\text { 20107-Rice--based beverage, plain } \\
\text { 20108-Oat-based beverage plain } \\
\text { 20202 - Soy-based beverage, flavored, fortified }\end{array}$ \\
\hline
\end{tabular}


Table A1. Cont.

\begin{tabular}{|c|c|c|}
\hline Variable & Definition & Austnut 2007 Food Codes \\
\hline $\begin{array}{l}\mathrm{DED}_{\text {food + dairy }} \\
\text { beverages }\end{array}$ & $\begin{array}{l}\text { All solid and liquid foods } \\
\text { including all dairy and } \\
\text { dairy-substitute based } \\
\text { beverages, dairy } \\
\text { beverage flavorings, } \\
\text { infant/toddler formula } \\
\text { and breastmilk }\end{array}$ & $\begin{array}{l}\text { 20203-Soy-based beverage, reduced fat, flavored } \\
\text { 20204-Soy-based beverage, reduced fat, flavored, fortified } \\
\text { 22204023-Almond milk with linseed oil and water } \\
\text { 30102002-Breakfast cereal, beverage, all flavours, added vitamins A, B1, B2, C } \\
\text { \& folate } \\
\text { 30103-Milk-based powder replacements } \\
\text { 30104-Oral supplement liquids } \\
\text { 30105-Oral supplement powders } \\
\text { 32101-Infant formula } \\
\text { 32102-Human breast milk } \\
\text { 32103-Toddler formula, milk based } \\
\text { Excluded major codes were: } \\
\text { 11-Non-alcoholic beverages, } \\
\text { 30-Special dietary foods } \\
\text { 33-Dietary supplements. }\end{array}$ \\
\hline $\begin{array}{l}\mathrm{DED}_{\text {food + all }} \\
\text { beverages }\end{array}$ & $\begin{array}{l}\text { All solid and liquid foods } \\
\text { and all beverages } \\
\text { including water }\end{array}$ & $\begin{array}{l}\text { All food codes included in } \mathrm{DED}_{\text {food }} \text { and } \mathrm{DED}_{\text {food }}+\text { dairy beverages } \\
\text { the below additional codes; } \\
\text { 11-Non-alcoholic beverages } \\
11805 \text {-Other beverages (e.g., probiotics) } \\
27303005 \text {-Ice confection drink, crushed ice with fruit-based flavored syrup ( } 25 \% \\
\text { apple juice) } \\
27303006 \text {-Ice confection, } 97 \% \text { fruit juice, tropical (apple, mango, passionfruit } \\
\text { and banana) } \\
\text { 32401-Infant fruit juices } \\
\text { Excluded major codes were: } \\
\text { 30-Special dietary foods } \\
\text { 33-Dietary supplements. }\end{array}$ \\
\hline
\end{tabular}

\section{References}

1. World Cancer Research Fund/American Institute for Cancer Research. Food, Nutrition, Physical Activity, and the Prevention of Cancer: A Global Perspective; American Institute for Cancer Research: Washington, DC, USA, 2007.

2. Australian Bureau of Statistics. National Health Survey: First Results, 2014-15; Australian Bureau of Statistics: Canberra, Australia, 2015.

3. Must, A.; Strauss, R.S. Risks and consequences of childhood and adolescent obesity. Int. J. Obes. 1999, 23, S2-S11. [CrossRef]

4. Reilly, J.J.; Kelly, J. Long-term impact of overweight and obesity in childhood and adolescence on morbidity and premature mortality in adulthood: Systematic review. Int. J. Obes. 2010, 35, 891. [CrossRef] [PubMed]

5. Perez-Escamilla, R.; Obbagy, J.E.; Altman, J.M.; Essery, E.V.; McGrane, M.M.; Wong, Y.P.; Spahn, J.M.; Williams, C.L. Dietary energy density and body weight in adults and children: A systematic review. J. Acad. Nutr. Diet. 2012, 112, 671-684. [CrossRef] [PubMed]

6. Rouhani, M.H.; Haghighatdoost, F.; Surkan, P.J.; Azadbakht, L. Associations between dietary energy density and obesity: A systematic review and meta-analysis of observational studies. Nutrition 2016, 32, 1037-1047. [CrossRef] [PubMed]

7. Fisher, J.O.; Liu, Y.; Birch, L.L.; Rolls, B.J. Effects of portion size and energy density on young children's intake at a meal. Am. J. Clin. Nutr. 2007, 86, 174-179. [PubMed]

8. Leahy, K.E.; Birch, L.L.; Rolls, B.J. Reducing the energy density of multiple meals decreases the energy intake of preschool-age children. Am. J. Clin. Nutr. 2008, 88, 1459-1468. [CrossRef] [PubMed]

9. Leahy, K.E.; Birch, L.L.; Fisher, J.O.; Rolls, B.J. Reductions in Entrée Energy Density Increase Children's Vegetable Intake and Reduce Energy Intake. Obesity 2008, 16, 1559-1565. [CrossRef] [PubMed]

10. Leahy, K.E.; Birch, L.L.; Rolls, B.J. Reducing the Energy Density of an Entrée Decreases Children's Energy Intake at Lunch. J. Am. Diet. Assoc. 2008, 108, 41-48. [CrossRef] [PubMed]

11. Vernarelli, J.A.; Mitchell, D.C.; Hartman, T.J.; Rolls, B.J. Dietary Energy Density Is Associated with Body Weight Status and Vegetable Intake in US Children. J. Nutr. 2011, 141, 2204-2210. [CrossRef] [PubMed] 
12. Hebestreit, A.; Bornhorst, C.; Pala, V.; Barba, G.; Eiben, G.; Veidebaum, T.; Hadjigergiou, C.; Molnár, D.; Claessens, M.; Fernández-Alvira, J.M.; et al. Dietary energy density in young children across Europe. Int. J. Obes. (Lond.) 2014, 38 (Suppl. 2), S124-S134. [CrossRef] [PubMed]

13. Ledikwe, J.H.; Blanck, H.M.; Khan, L.K.; Serdula, M.K.; Seymour, J.D.; Tohill, B.C.; Rolls, B.J. Dietary Energy Density Determined by Eight Calculation Methods in a Nationally Representative United States Population. J. Nutr. 2005, 135, 273-278. [CrossRef] [PubMed]

14. Johnson, L.; Wilks, D.C.; Lindroos, A.K.; Jebb, S.A. Reflections from a systematic review of dietary energy density and weight gain: Is the inclusion of drinks valid? Obes. Rev. 2009, 10, 681-692. [CrossRef] [PubMed]

15. Department of Health and Ageing. Australian Dietary Guidelines; Commonwealth of Australia: Canberra, Australia, 2013.

16. Australian Bureau of Statistics. Australian Health Survey: Nutrition First Results_Food and Nutrients, 2011-12; Australian Bureau of Statistics: Canberra, Australia, 2014.

17. Kral, T.V.E.; Berkowitz, R.I.; Stunkard, A.J.; Stallings, V.A.; Brown, D.D.; Faith, M.S. Dietary energy density increases during early childhood irrespective of familial predisposition to obesity: Results from a prospective cohort study. Int. J. Obes. (Lond.) 2007, 31, 1061-1067. [CrossRef] [PubMed]

18. Gunther, A.L.; Stahl, L.J.; Buyken, A.E.; Kroke, A. Association of dietary energy density in childhood with age and body fatness at the onset of the pubertal growth spurt. Br. J. Nutr. 2011, 106, 345-349. [CrossRef] [PubMed]

19. Wake, M.; Hardy, P.; Canterford, L.; Sawyer, M.; Carlin, J.B. Overweight, obesity and girth of Australian preschoolers: Prevalence and socio-economic correlates. Int. J. Obes. (Lond.) 2007, 31, 1044-1051. [CrossRef] [PubMed]

20. Davison, K.K.; Birch, L.L. Childhood overweight: A contextual model and recommendations for future research. Obes. Rev. 2001, 2, 159-171. [CrossRef] [PubMed]

21. Parsons, T.J.; Power, C.; Logan, S.; Summerbell, C.D. Childhood predictors of adult obesity: A systemic review. Int. J. Obes. 1999, 23, S1-S107.

22. Wang, Y.; Beydoun, M.A.; Li, J.; Moreno, L.A. Do children and their parents eat a similar diet? Resemblance in child and parental dietary intake: Systematic review and meta-analysis. J. Epidemiol. Community Health 2011, 65, 117-189. [CrossRef] [PubMed]

23. Gebremariam, M.K.; Vaque-Crusellas, C.; Andersen, L.F.; Stok, F.M.; Stelmach-Mardas, M.; Brug, J.; Lien, N. Measurement of availability and accessibility of food among youth: A systematic review of methodological studies. Int. J. Behav. Nutr. Phys. Act. 2017, 14, 22. [CrossRef] [PubMed]

24. Shrewsbury, V.; Wardle, J. Socioeconomic status and adiposity in childhood: A systematic review of cross-sectional studies 1990-2005. Obesity (Silver Spring) 2008, 16, 275-284. [CrossRef] [PubMed]

25. Kant, A.K.; Graubard, B.I. Family income and education were related with 30 -year time trends in dietary and meal behaviors of American children and adolescents. J. Nutr. 2013, 143, 690-700. [CrossRef] [PubMed]

26. Campbell, K.; Hesketh, K.; Crawford, D.; Salmon, J.; Ball, K.; McCallum, Z. The Infant Feeding Activity and Nutrition Trial (INFANT) an early intervention to prevent childhood obesity: Cluster-randomised controlled trial. BMC Public Health 2008, 8, 103. [CrossRef] [PubMed]

27. Hesketh, K.D.; Campbell, K.; Salmon, J.; McNaughton, S.A.; McCallum, Z.; Cameron, A.; Ball, K.; Gold, L.; Andrianopoulos, N.; Crawford, D. The Melbourne Infant Feeding, Activity and Nutrition Trial (InFANT) Program follow-up. Contemp. Clin. Trials 2013, 34, 145-151. [CrossRef] [PubMed]

28. Campbell, K.J.; Lioret, S.; McNaughton, S.A.; Crawford, D.A.; Salmon, J.; Ball, K.; McCallum, Z.; Gerner, B.E.; Spence, A.C.; Cameron, A.J.; et al. A Parent-Focused Intervention to Reduce Infant Obesity Risk Behaviors: A Randomized Trial. Pediatrics 2013, 131, 652-660. [CrossRef] [PubMed]

29. Subar, A.F.; Thompson, F.E.; Potischman, N.; Forsyth, B.H.; Buday, R.; Richards, D.; McNutt, S.; Hull, S.G.; Guenther, P.M.; Schatzkin, A.; et al. Formative research of a quick list for an automated self-administered 24-hour dietary recall. J. Am. Diet. Assoc. 2007, 107, 1002-1007. [CrossRef] [PubMed]

30. Conway, J.M.; Ingwersen, L.A.; Moshfegh, A.J. Accuracy of dietary recall using the USDA five-step multiple-pass method in men: An observational validation study. J. Am. Diet. Assoc. 2004, 104, 595-603. [CrossRef] [PubMed]

31. Grewal, N.K.; Mosdol, A.; Aunan, M.B.; Monsen, C.; Torheim, L.E. Development and pilot testing of 24-hour multiple-pass recall to assess dietary intake of toddlers of Somali- and Iraqi-born mothers living in Norway. Nutrients 2014, 6, 2333-2347. [CrossRef] [PubMed] 
32. Food Standards Australia New Zealand. AUSNUT 2007. 2015-2017. Available online: http:/ /www.foodstandards. gov.au/science/monitoringnutrients/ausnut/Pages/ausnut2007.aspx/ (accessed on 23 May 2017).

33. McCaffrey, T.A.; Rennie, K.L.; Kerr, M.A.; Wallace, J.M.; Hannon-Fletcher, M.P.; Coward, W.A.; Jebb, S.A.; Livingstone, M.B.E. Energy density of the diet and change in body fatness from childhood to adolescence; is there a relation? Am. J. Clin. Nutr. 2008, 87, 1230-1237. [PubMed]

34. Spence, A.C.; Campbell, K.C.; Crawford, D.A.; McNaughton, S.A.; Hesketh, K.D. Mediators of improved child diet quality following a health promotion intervention: The Melbourne InFANT Program. Int. J. Behav. Nutr. Phys. Act. 2014, 11, 137. [CrossRef] [PubMed]

35. Ireland, P.; Jolley, D.; Giles, G. Development of the Melbourne FFQ: A food frequency questionnaire for use in an Australian prospective study involving an ethnically diverse cohort. Asia Pac. J. Clin. Nutr. 1994, 19, 19-31.

36. MacFarlane, A.; Crawford, D.; Worsley, A. Associations between parental concern for adolescent weight and the home food environment and dietary intake. J. Nutr. Educ. Behav. 2010, 42, 152-160. [CrossRef] [PubMed]

37. Collins, L.J.; Lacy, K.E.; Campbell, K.J.; McNaughton, S.A. The Predictors of Diet Quality among Australian Children Aged 3.5 Years. J. Acad. Nutr. Diet. 2016, 116, 1114-1126.e2. [CrossRef] [PubMed]

38. Cameron, A.J.; Ball, K.; Hesketh, K.D.; McNaughton, S.A.; Salmon, J.; Crawford, D.A.; Lioret, S.; Campbell, K.J. Variation in outcomes of the Melbourne Infant, Feeding, Activity and Nutrition Trial (InFANT) Program according to maternal education and age. Prev. Med. 2014, 58, 58-63. [CrossRef] [PubMed]

39. Williamson, E.J.; Aitken, Z.; Lawrie, J.; Dharmage, S.C.; Burgess, J.A.; Forbes, A.B. Introduction to causal diagrams for confounder selection. Respirology 2014, 19, 303-311. [CrossRef] [PubMed]

40. Hendrie, G.A.; Coveney, J.; Cox, D. Exploring nutrition knowledge and the demographic variation in knowledge levels in an Australian community sample. Public Health Nutr. 2008, 11, 1365-1371. [CrossRef] [PubMed]

41. McLeod, E.R.; Campbell, K.J.; Hesketh, K.D. Nutrition knowledge: A mediator between socioeconomic position and diet quality in Australian first-time mothers. J. Am. Diet. Assoc. 2011, 111, 696-704. [CrossRef] [PubMed]

42. Fulkerson, J.A.; Friend, S.; Horning, M.; Flattum, C.; Draxten, M.; Neumark-Sztainer, D.; Gurvich, O.; Garwick, A.; Story, M.; Kubik, M.Y. Family Home Food Environment and Nutrition-Related Parent and Child Personal and Behavioral Outcomes of the Healthy Home Offerings via the Mealtime Environment (HOME) Plus Program: A Randomized Controlled Trial. J. Acad. Nutr. Diet. 2017. [CrossRef] [PubMed]

43. McGowan, L.; Croker, H.; Wardle, J.; Cooke, L.J. Environmental and individual determinants of core and non-core food and drink intake in preschool-aged children in the United Kingdom. Eur. J. Clin. Nutr. 2012, 66, 322-328. [CrossRef] [PubMed]

44. Spurrier, N.J.; Magarey, A.A.; Golley, R.; Curnow, F.; Sawyer, M.G. Relationships between the home environment and physical activity and dietary patterns of preschool children: A cross-sectional study. Int. J. Behav. Nutr. Phys. Act. 2008, 5, 31. [CrossRef] [PubMed]

45. Van der Horst, K.; Oenema, A.; Ferreira, I.; Wendel-Vos, W.; Giskes, K.; Van Lenthe, F.; Brug, J. A systematic review of environmental correlates of obesity-related dietary behaviors in youth. Health Educ. Res. 2007, 22, 203-226. [CrossRef] [PubMed]

46. Amuta, A.O.; Jacobs, W.; Idoko, E.E.; Barry, A.E.; McKyer, E.L. Influence of the Home Food Environment on Children's Fruit and Vegetable Consumption: A Study of Rural Low-Income Families. Health Promot. Pract. 2015, 16, 689-698. [CrossRef] [PubMed]

47. Pearson, N.; Biddle, S.J.; Gorely, T. Family correlates of fruit and vegetable consumption in children and adolescents: A systematic review. Public Health Nutr. 2009, 12, 267-283. [CrossRef] [PubMed]

48. Wyse, R.; Campbell, E.; Nathan, N.; Wolfenden, L. Associations between characteristics of the home food environment and fruit and vegetable intake in preschool children: A cross-sectional study. BMC Public Health 2011, 11, 938. [CrossRef] [PubMed]

49. Drewnowski, A. The real contribution of added sugars and fats to obesity. Epidemiol. Rev. 2007, $29,160-171$. [CrossRef] [PubMed]

50. Boots, S.B.; Tiggemann, M.; Corsini, N.; Mattiske, J. Managing young children's snack food intake. The role of parenting style and feeding strategies. Appetite 2015, 92, 94-101. [CrossRef] [PubMed] 
51. Robinson, L.N.; Rollo, M.E.; Watson, J.; Burrows, T.L.; Collins, C.E. Relationships between dietary intakes of children and their parents: A cross-sectional, secondary analysis of families participating in the Family Diet Quality Study. J. Hum. Nutr. Diet. 2015, 28, 443-451. [CrossRef] [PubMed]

52. Robson, S.M.; Couch, S.C.; Peugh, J.L.; Glanz, K.; Zhou, C.; Sallis, J.F.; Saelens, B.E. Parent Diet Quality and Energy Intake Are Related to Child Diet Quality and Energy Intake. J. Acad. Nutr. Diet. 2016, 116, 984-990. [CrossRef] [PubMed]

53. Fisher, J.; Mitchell, D.C.; Smiciklas-Wrightt, H.; Birch, L.L. Parental influences on young girls' fruit and vegetables, micronutrient and fat intake. J. Am. Diet. Assoc. 2002, 102, 58-64. [CrossRef]

54. Walsh, A.D.; Cameron, A.J.; Crawford, D.; Hesketh, K.D.; Campbell, K.J. Dietary associations of fathers and their children between the ages of 20 months and 5 years. Public Health Nutr. 2016, 19, 2033-2039. [CrossRef] [PubMed]

55. Rasmussen, M.; Krolner, R.; Klepp, K.I.; Lytle, L.; Brug, J.; Bere, E.; Due, P. Determinants of fruit and vegetable consumption among children and adolescents: A review of the literature. Part I: Quantitative studies. Int. J. Behav. Nutr. Phys. Act. 2006, 3, 22. [CrossRef] [PubMed]

56. Durao, C.; Severo, M.; Oliveira, A.; Moreira, P.; Guerra, A.; Barros, H.; Lopes, C. Association of maternal characteristics and behaviours with 4-year-old children's dietary patterns. Matern. Child Nutr. 2017, 13. [CrossRef] [PubMed]

57. Vilela, S.; Oliveira, A.; Pinto, E.; Moreira, P.; Barros, H.; Lopes, C. The influence of socioeconomic factors and family context on energy-dense food consumption among 2-year-old children. Eur. J. Clin. Nutr. 2015, 69, 47-54. [CrossRef] [PubMed]

58. Johnson, L.; Mander, A.P.; Jones, L.R.; Emmett, P.M.; Jebb, S.A. A prospective analysis of dietary energy density at age 5 and 7 years and fatness at 9 years among UK children. Int. J. Obes. (Lond.) 2008, 32, 586-593. [CrossRef] [PubMed]

59. Hebestreit, A.; Bornhorst, C.; Barba, G.; Siani, A.; Huybrechts, I.; Tognon, G.; Eiben, G.; Moreno, L.A.; Fernández Alvira, J.M.; Loit, H.M.; et al. Associations between energy intake, daily food intake and energy density of foods and BMI z-score in 2-9-year-old European children. Eur. J. Nutr. 2014, 53, 673-681.

60. Patterson, E.; Warnberg, J.; Poortvliet, E.; Kearney, J.M.; Sjostrom, M. Dietary energy density as a marker of dietary quality in Swedish children and adolescents: The European Youth Heart Study. Eur. J. Clin. Nutr. 2010, 64, 356-363. [CrossRef] [PubMed]

61. Rehm, C.D.; Drewnowski, A. A new method to monitor the contribution of fast food restaurants to the diets of US children. PLoS ONE 2014, 9, e103543. [CrossRef] [PubMed]

62. Skala, K.; Chuang, R.J.; Evans, A.; Hedberg, A.M.; Dave, J.; Sharma, S. Ethnic differences in the home food environment and parental food practices among families of low-income Hispanic and African-American preschoolers. J. Immigr. Minor. Health 2012, 14, 1014-1022. [CrossRef] [PubMed] 